\title{
Arquitetura interna e petrografia do derrame Salto do Lontra, sudoeste do estado do Paraná.
}

\author{
Internal architecture and petrography of the Salto do Lontra flow, southwestern state of Paraná. \\ CARLOS HENRIQUE NALIN FERREIRA', MARIA JOSÉ MALUF DE MESQUITA², MÁRCIA ELISA BOSCATO GOMES ${ }^{3}$, \\ PATRICIA HILLEBRANDT ${ }^{1}$, ELEONORA MARIA GOUVÊA VASCONCELLOS ${ }^{1}$ \\ 'Universidade Federal do Paraná - UFPR, PR - caiqueufpr@gmail.com, paty_sbs@hotmail.com, eleonora@ufpr.br \\ ${ }^{2}$ Universidade Estadual de Campinas - UNICAMP, SP - mesquita.mariajose@gmail.com \\ ${ }^{3}$ Universidade Federal do Rio Grande do Sul -UFRGS, RS -00010352@ufrgs.br
}

\begin{abstract}
Resumo
O derrame Salto do Lontra está inserido na Província Magmática do Paraná e localiza-se no sudoeste do Estado do Paraná. O derrame possui $50 \mathrm{~m}$ de espessura e apresenta distribuição, arranjo de suas estruturas internas e padrões de fraturas bem definidos. Estas características permitem a divisão do derrame em: nível vesicular de topo, nível maciço central e nível vesicular de base. Estas características definem a arquitetura interna e sugerem que o derrame foi formado por processos de inflamento e se resfriou como um único corpo de lava, das bordas para o centro. Ocorrem corpos de pegmatito básico, com formas alongadas, alojados no terço superior do derrame. Estes corpos têm assembleia mineral semelhante aos basaltos encaixantes e são diferenciados principalmente pela granulação e presença de amígdalas. Os basaltos e pegmatitos possuem assembleia mineral primária constituída principalmente por andesina, augita, magnetita, ilmenita e apatita, e secundária por clorita e hematita. Caracterizar a arquitetura dos derrames é fundamental para subsidiar o entendimento dos processos formadores dos derrames basálticos, bem como desenvolver modelos metalogenéticos e guias prospectivos para a Província Magmática do Paraná.
\end{abstract}

Palavras-chave: Salto do Lontra; arquitetura interna; basalto; pegmatito.

\begin{abstract}
The Salto do Lontra flow, included in Paraná Magmatic Province, is located in southwestern State of Paraná, northern Salto do Lontra City. The flow is $50 \mathrm{~m}$ thick can be divided into three portions according to structure and fracture pattern: top vesicular level, center massive level and base vesicular level. These characteristics define the internal architecture and suggest that the flow was formed by inflation processes and cooled as an only body from the boundaries to the center. Bodies of basic pegmatite occur as sheets at the upper third of the flow. Both basic pegmatite and host basalt have similar mineral assemblage, which can be differentiated by grain size and the presence of amygdales. The primary mineral assemblage of the basalt and pegmatite is composed by andesine, augite, magnetite, ilmenite and apatite; chlorite and hematite became as a secondary mineral assemblage. Individualize and Characterize the architecture of basalt flows is critical to support the understanding the flows formation processes and to develop exploration metallogenic models and the prospective guides to the Paraná Magmatic Province.
\end{abstract}

Keywords: Salto do Lontra; internal architecture; basalt; pegmatite.

\section{INTRODUÇÃO}

O derrame Salto do Lontra está localizado a cerca de três quilômetros a norte da Cidade de Salto do Lontra, descrito na PEDREIRA BONETTI (Figura 1). A região é composta por rochas pertencentes à Província Magmática do Paraná (PMP), onde afloram predominantemente rochas ígneas basálticas formando derrames tabulares espessos ou Tipo II (Gomes 1996). Ocorrem também rochas diferenciadas, classificadas como gabros pegmatoides (Vasconcellos et al. 2001) e como pegmatitos básicos (Kontak et al. 2004) no núcleo destes derrames. 


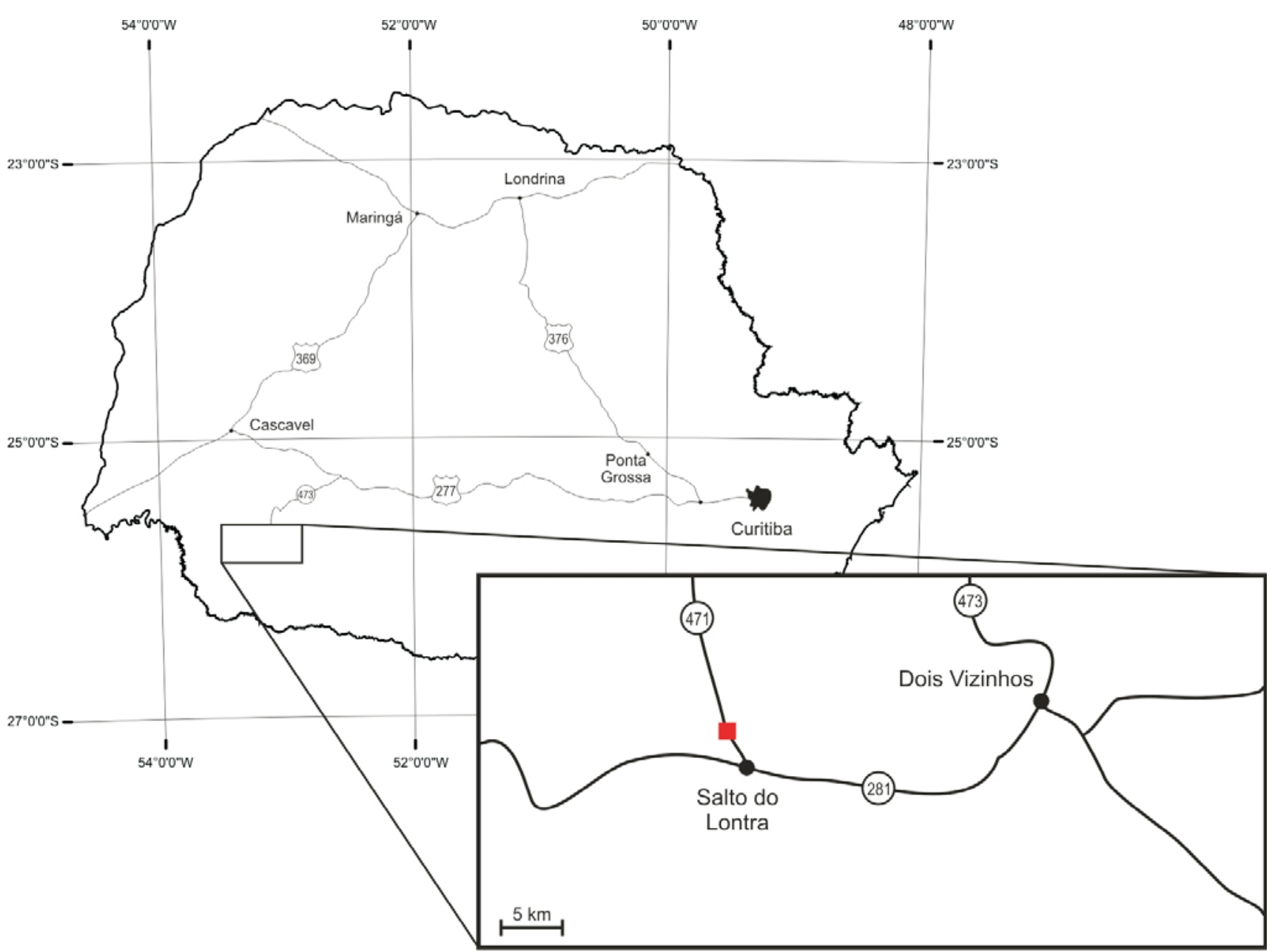

Figura 1 - Localização da Pedreira Bonetti (quadrado vermelho)

Vários derrames espessos já foram descritos no sul do Brasil, na PMP, a partir da observação da distribuição e padrão das estruturas internas. Gomes (1996), Ferreira (2008) e Dutra (2009) descreveram a ocorrência de derrames espessos possivelmente formados a partir de processos contínuos de inflamento. A importância em se compreender a estruturação interna de um derrame deve-se ao fato de que, segundo Gomes (1996), esta reflete diretamente a história evolutiva e o resfriamento deste.

Corpos pegmatíticos foram descritos por Arioli et al. (2008) na região sudeste do Estado do Paraná como lentes com espessura de poucos centímetros até cerca de $70 \mathrm{~cm}$ e extensão que ultrapassa $50 \mathrm{~m}$ encaixados no nível maciço central de derrames espessos de basalto.

\section{ARQUITETURA INTERNA}

Os horizontes que compõem o derrame são individualizados, principalmente, de acordo com a distribuição das estruturas internas, como: vesículas, amígdalas e diferentes padrões de fraturas.

No perfil esquemático (Figura 2), os horizontes $2,3 a, 3 b, 3 c$ e 4 representam a arquitetura do derrame Salto do Lontra. Os horizontes 1 e 5, representam os derrames sobreposto e sotoposto ao Salto do Lontra, respectivamente. 

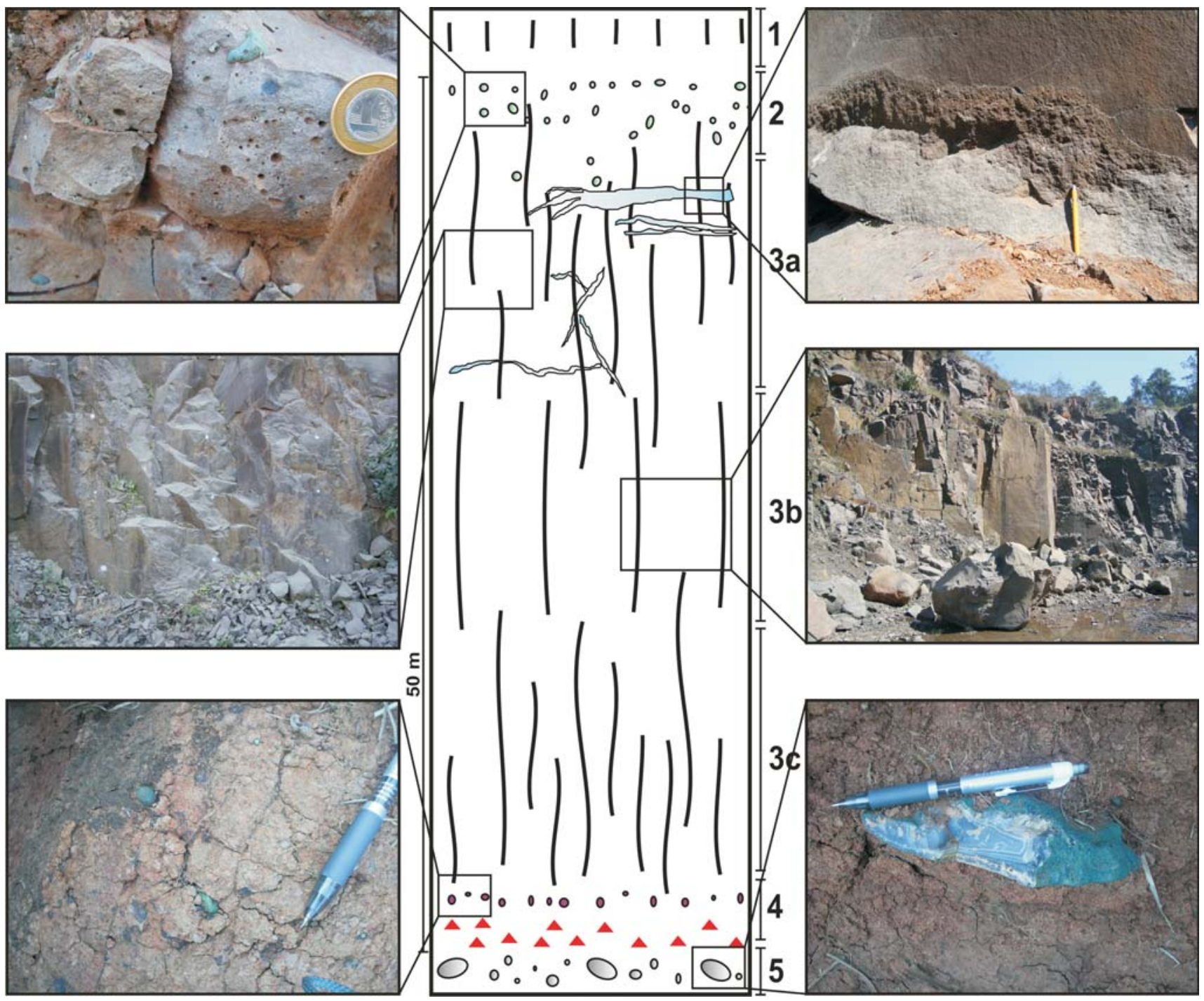

Figura 2 - Perfil esquemático do derrame Salto do Lontra, base do derrame superior e topo do derrame sotoposto; divididos em seis horizontes. 1-Base do derrame sobreposto ao Salto do Lontra, composto por basalto cinza claro e estrutura maciça. 2-Nível vesicular de topo do Salto do Lontra, composto por basalto pouco alterado e variolítico. 3a - Horizonte superior do nível maciço central, caracterizado por fraturas pouco contínuas e presença de pegmatitos básicos. 3b - Horizonte mediano do NMC, definido por fraturas regulares, retilíneas a curvilíneas, formando prismas. 3c-Horizonte inferior do NMC; possui fraturas pouco regulares e mais descontínuas. 4-Nível vesicular de base do Salto do Lontra, caracterizado por apresentar rocha alterada, poucas vesículas e pequenas brechas. 5 - Nível vesicular superior do derrame sotoposto ao Salto do Lontra.

Foram individualizados três horizontes principais em perfil vertical ao derrame: nível vesicular de topo (NVT), nível maciço central (NMC) e nível vesicular de base (NVB).

O NVT, horizonte 2 , possui entre dois a três metros de espessura e consiste em um horizonte onde a principal característica é a grande quantidade de vesículas, amígdalas e alguns geodos, caracterizando estrutura variolítica (Figura 3a).

As amígdalas presentes neste nível dividem-se em duas populações " $A$ " e " $B$ ". A população " $A$ ", é representada por amígdalas cujos tamanhos variam de milimétricas até cerca de $1-1,5 \mathrm{~cm}$. São geralmente monominerálicas, arredondadas e ligeiramente achatadas; podem estar orientadas em uma direção preferencial (Figura 3b). As amígdalas da população "A" são preenchidas por quartzo, esmectita e celadonita principalmente. A população "B" é representada por amígdalas maiores, com cerca de $5 \mathrm{~cm}$, que apresentam bordas irregulares (Figura 3c), estas são preenchidas por quartzo com celadonita nas bordas.

Os geodos têm formas irregulares e tamanhos que variam de alguns centímetros até aproximadamente $50 \mathrm{~cm}$ de comprimento, são preenchidos principalmente por quartzo.

As vesículas, sem preenchimento, presentes neste horizonte apresentam tamanhos que variam de milimétricos até cerca de $1 \mathrm{~cm}$, podem ser divididas em dois grupos principais A e B.

As vesículas do grupo $A$ são arredondadas ou ligeiramente achatadas, aparentemente sem orientação e distribuem-se de forma homogênea no nível, em 
conjunto com as amígdalas.

As vesículas do grupo B possuem forma semelhante as do grupo A, porém por vezes apresentamse orientadas em uma direção preferencial. A principal característica do grupo de vesículas B é a ocorrência em forma de aglomerados, como pode ser observado na
Figura 3d. Este grupo localiza-se no topo do nível vesicular superior.

As vesículas encontram-se também em estruturas horizontais formando pequenas lentes, formando estruturas tipo lençóis de vesículas.
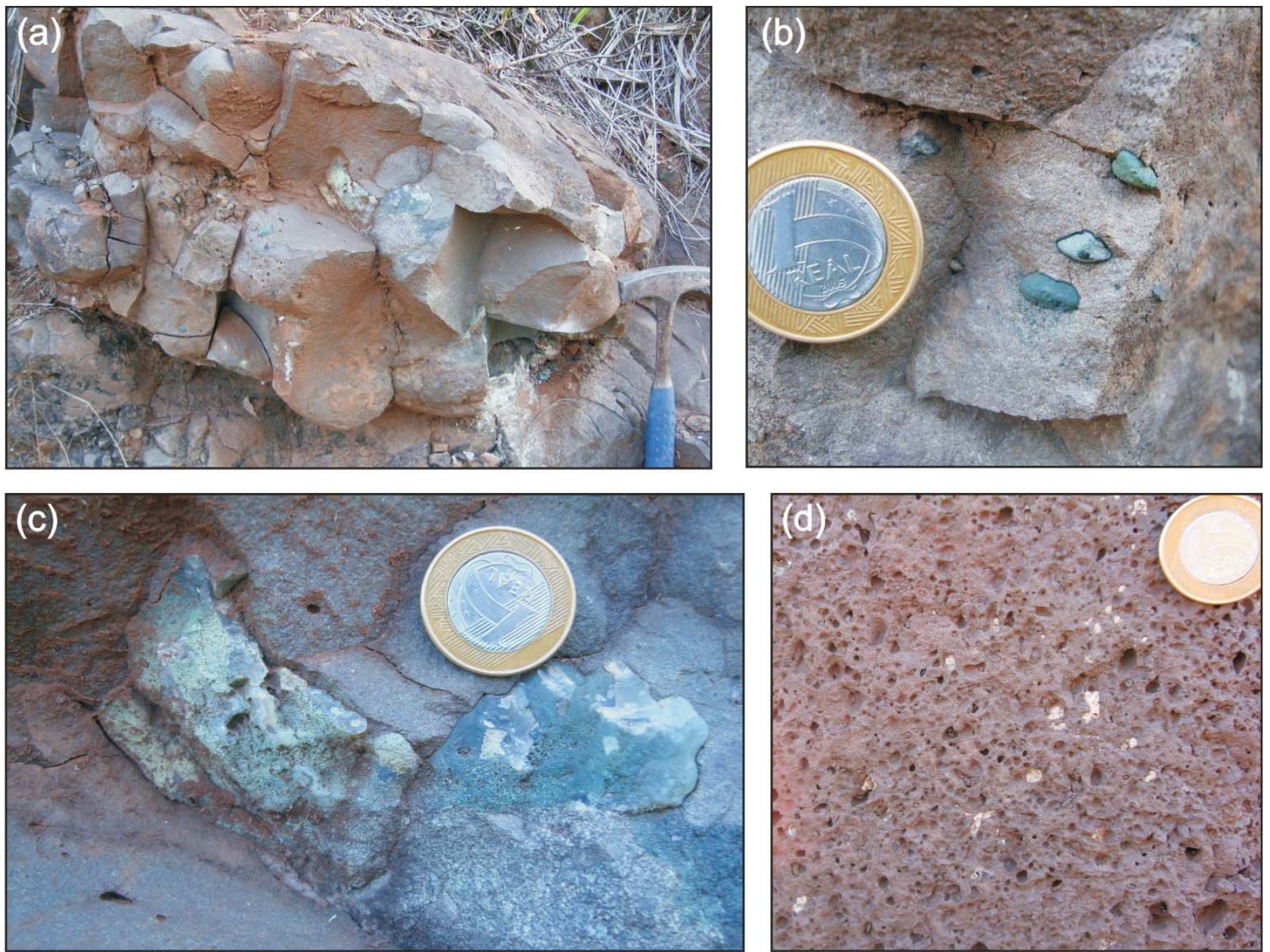

Figura 3 - Fotografias do nível vesicular de topo do derrame Salto do Lontra. (a) afloramento de basalto variolítico, cinza avermelhado, com presença de amígdalas e vesículas milimétricas a centimétricas; (b) amígdalas milimétricas achatadas e preenchidas por celadonita; (c) amígdala com forma irregular preenchida por quartzo microcristalino e celadonita; (d) concentração de vesículas presentes na porção superior do nível vesicular de topo.

O nível maciço central, horizonte 3 , representa cerca de $90 \%$ ou 45 metros da espessura total do derrame e está compreendido entre os níveis vesiculares de topo e de base, com os quais faz contato gradual.

Este nível é diferenciado dos demais, principalmente, por apresentar estrutura maciça, padrões de fraturas mais regulares e ausência de amígdalas e vesículas.

O NMC pode ser dividido, seguindo critérios estruturais, em três horizontes: $3 a$ (topo), $3 b$ (meio) e $3 c$ (base). Cada horizonte possui cerca de 15 metros de espessura. As diferenças nos padrões estruturais dos horizontes $3 a$ e $3 b$ podem ser observados na Figura $4 a$.

O horizonte $3 a$ é caracterizado por apresentar um padrão de fraturas mais irregular. As fraturas são curvilíneas e descontínuas. A intersecção entre as famílias de fraturas geram prismas pequenos, com 30-50 $\mathrm{cm}$ de largura e 1-1,5 $\mathrm{m}$ de altura. Os prismas gerados possuem faces irregulares (Figura 4b). Além do padrão de fraturas, este horizonte destaca-se por apresentar corpos de pegmatito básico.

O horizonte $3 b$ tem padrão de fraturas mais regular, que divide a rocha em grandes prismas de três ou quatro lados. Os prismas possuem cerca de $3 \mathrm{~m}$ de largura e até 6 metros de altura (Figura 4c). As fraturas são sub-verticais, planares a curvilíveas e mais contínuas que as fraturas dos horizontes $3 a$ e $3 c$.

O horizonte $3 c$ apresenta padrão de fraturas também irregular, semelhante ao que ocorre no horizonte 3a, porém não ocorrem corpos pegmatíticos 
neste horizonte.
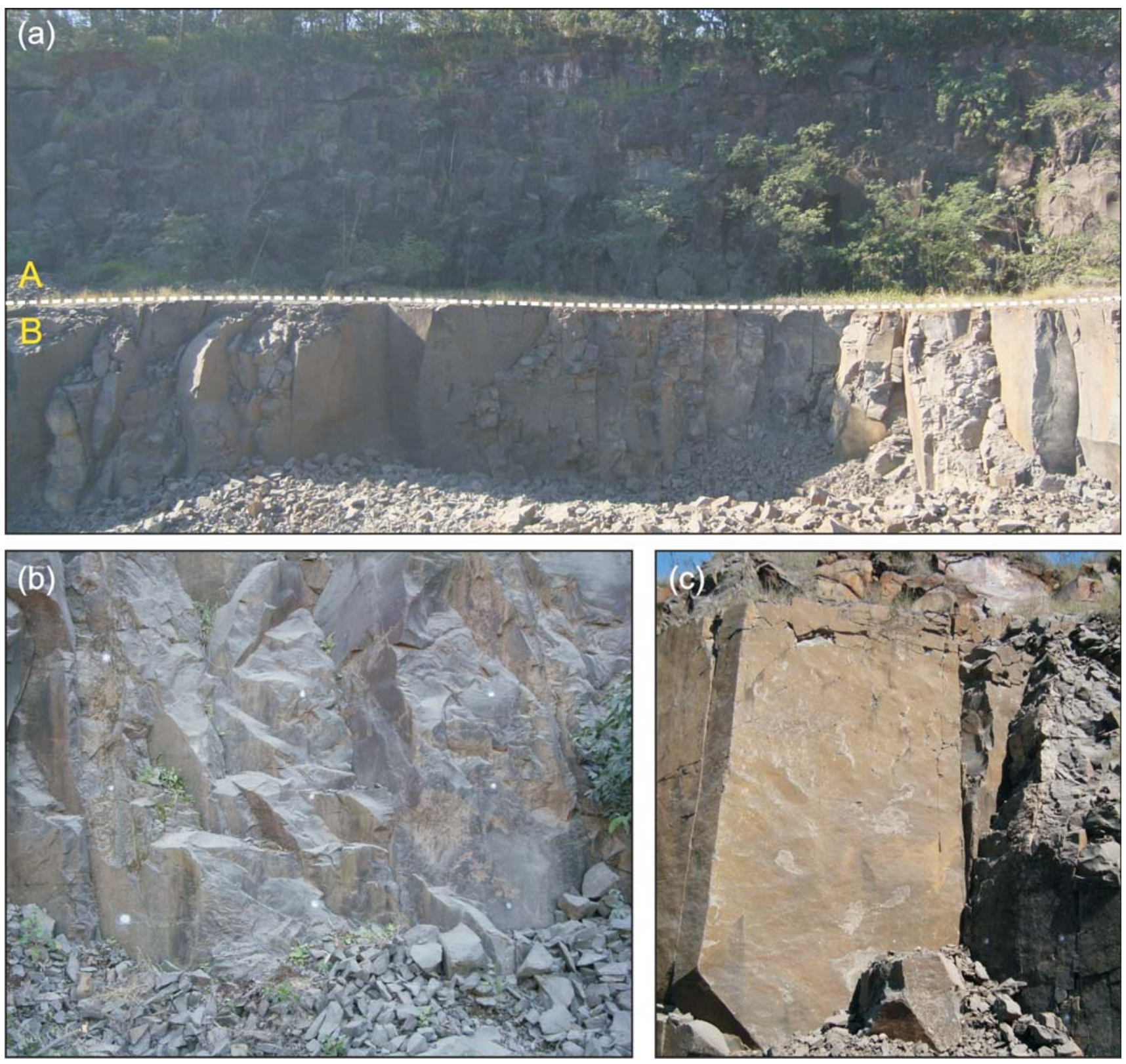

Figura 4 - Fotografias do nível maciço central do derrame Salto do Lontra. (a) seção vertical de parte do nível maciço central do derrame mostrando os horizontes $3 a(A)$ e $3 b(B)$; (b) detalhe das fraturas irregulares, sem muita continuidade presentes no horizonte 3a; (c) detalhe das fraturas retilíneas e mais regulares predominantes no horizonte $3 \mathrm{~b}$, formando prismas.

O nível vesicular de base não ultrapassa $50 \mathrm{~cm}$ de espessura e compõe, no perfil realizado, a parte inferior do derrame do Salto do Lontra. Este nível faz contato gradual com o horizonte 3 . O contato do nível vesicular de base do derrame Salto do Lontra com o nível vesicular superior do derrame sotoposto (Figura 5a) é relativamente bem definido.

Este nível é caracterizado por apresentar grande quantidade de amígdalas, caracterizando uma estrutura amigdaloidal; porém o número de amígdalas é menor que o encontrado no nível vesicular superior (Figura 5b).

As amígdalas encontradas neste nível têm tamanhos que variam de milimétricos até cerca de $4 \mathrm{~cm}$. Têm formas arredondadas e são, geralmente, monominerálicas. As amígdalas podem estar preenchidas por quartzo microcristalino e celadonita, principalmente. 

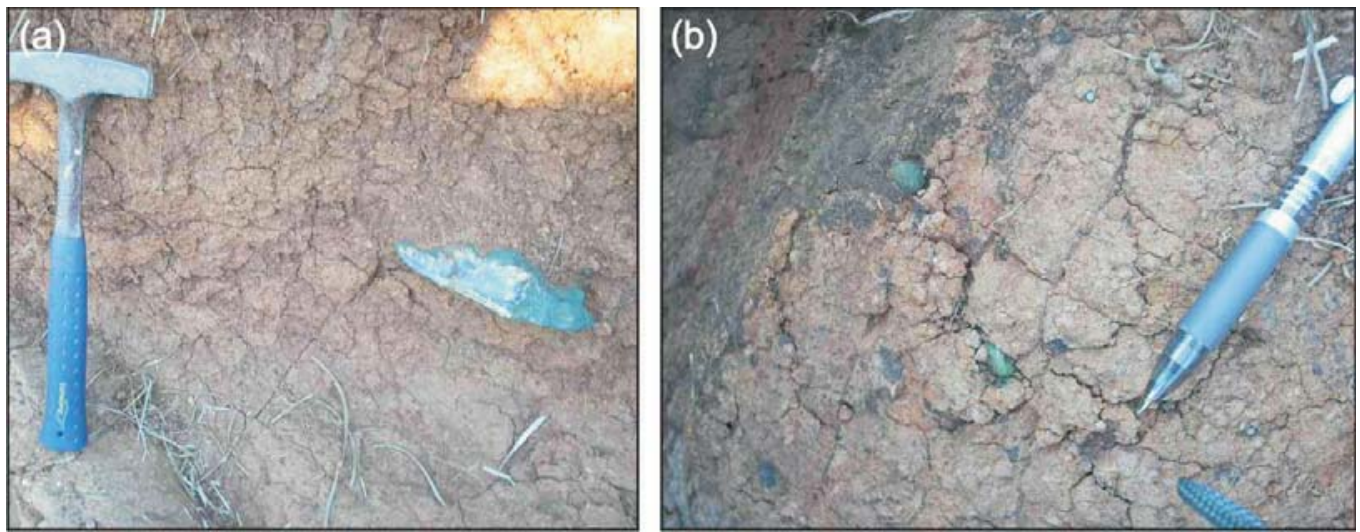

Figura 5 - Fotografias do nível vesicular de base do derrame Salto do Lontra e do nível vesicular superior do derrame sotoposto. (a) amígdala centimétrica preenchida por calcedônia e celadonita no nível vesicular superior do derrame sotoposto ao Salto do Lontra; (b) amígdalas milimétricas preenchidas por celadonita em basalto castanho avermelhado e alterado da base do derrame Salto do Lontra.

\subsection{Pegmatitos Básicos}

Os corpos de pegmatito básico ocorrem como lentes alongadas e pouco espessas no horizonte 3a do nível maciço central do derrame Salto do Lontra. Estes corpos possuem de poucos centímetros até cerca de $50 \mathrm{~cm}$ de espessura, porém sua extensão lateral pode chegar até a 5 metros (Figura 6). 0 contato destes corpos com o basalto encaixante pode ser relativamente bem definido em topo e base ou mais difuso e irregular em alguns casos.

Os corpos pegmatíticos podem ser divididos, principalmente, em dois tipos: A e B. Os pegmatitos tipo A configuram corpos cujas espessuras variam de poucos centímetros até cerca de $50 \mathrm{~cm}$ e extensão lateral de até 5 metros. Estes corpos fazem contatos relativamente bem definidos com o basalto encaixante (Figura 7a).

O tipo A é caracterizado por apresentar grande quantidade de amígdalas, estas estruturas chegam a perfazer cerca de $35 \%$ da rocha. Os corpos pegmatíticos tipo B são mais difíceis de serem reconhecidos em afloramento, pois possuem contatos mais irregulares e difusos com a encaixante (Figura 7b). Este tipo é característico por apresentar muito pouca ou nenhuma presença de amígdalas, e porosidade relativamente mais baixa em relação ao tipo $A$. Os cristais do pegmatito tipo $B$ são, aparentemente, maiores que os do tipo A, porém os corpos pegmatíticos tipo A ocorrem em maior quantidade e também possuem maior extensão lateral.
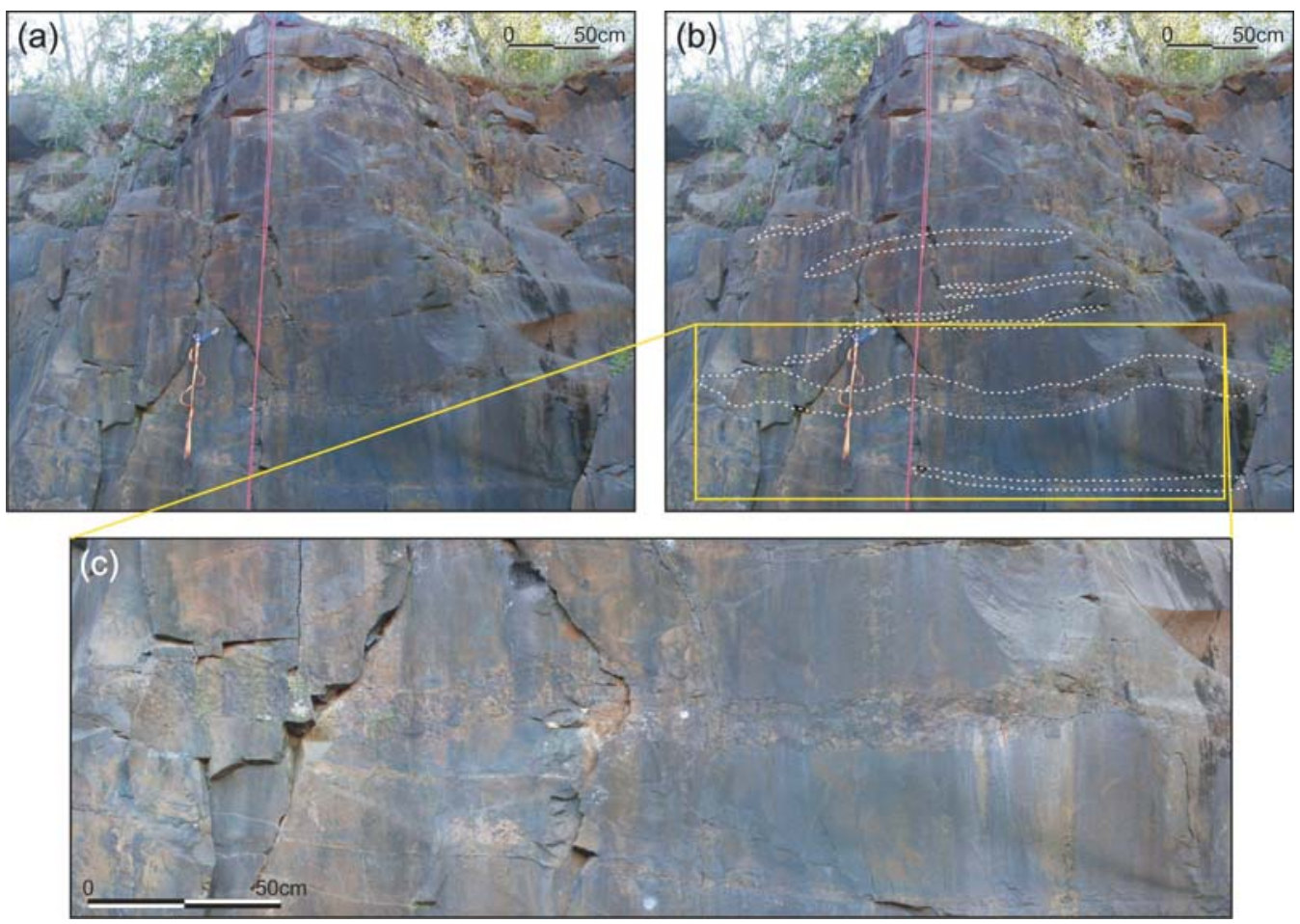

Figura 6 - Fotografias do Horizonte 3a do nível maciço central do derrame Salto do Lontra. (a) Porção superior do Horizonte 3a, com presença de lentes centimétricas de pegmatito básico encaixadas horizontalmente ao derrame. (b) Figura com pontilhado evidenciando os corpos pegmatíticos. (c) Aproximação em uma das maiores lentes de pegmatito básico aflorante, neste caso um pegmatito tipo $\mathrm{A}$. 

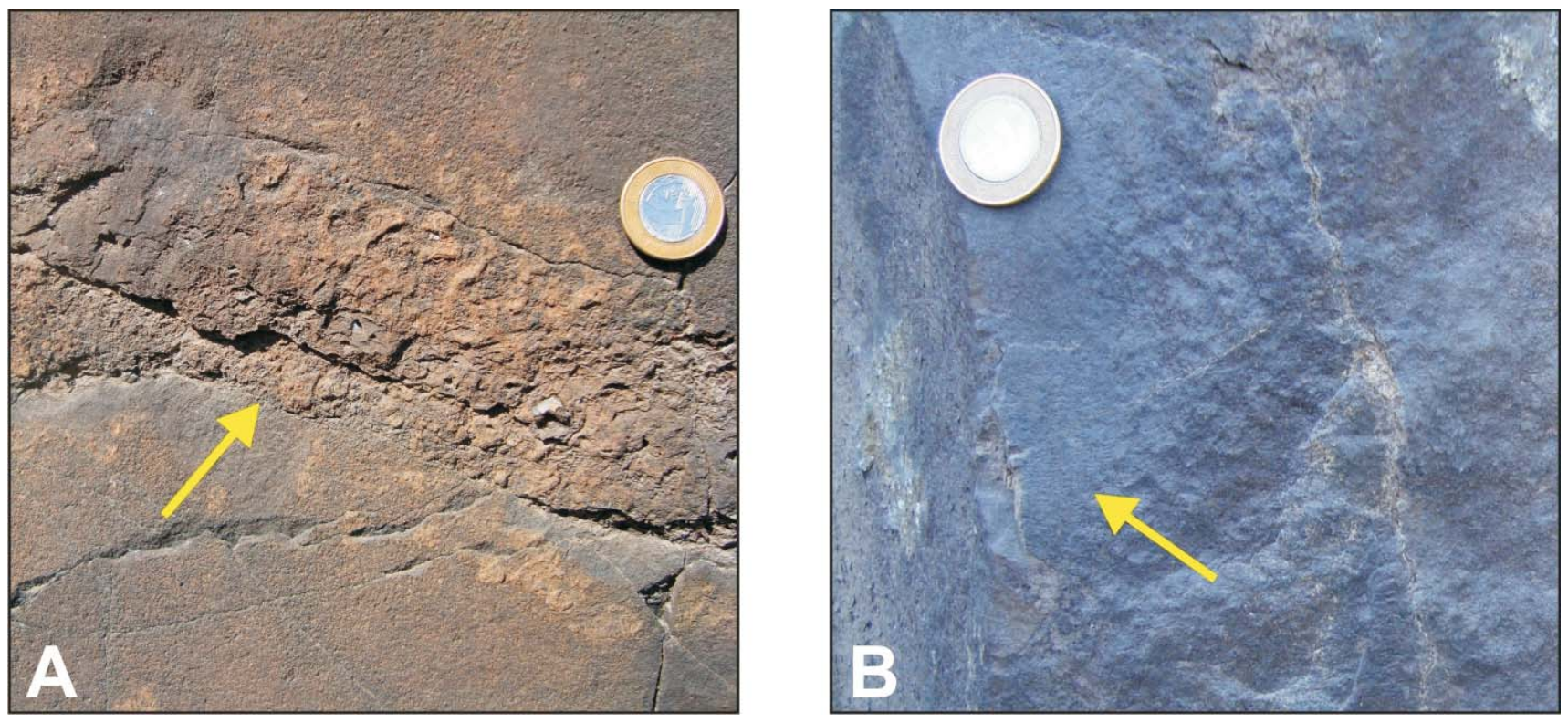

Figura 7 - Detalhe do contato dos tipos de pegmatitos com a encaixante. (A) Corpo de pegmatito básico tipo A, evidenciando contato relativamente melhor definido com a encaixante (flecha amarela). (B) Contato entre basalto encaixante e corpo de pegmatito básico tipo $B$, neste caso contato mais irregular, difuso e gradual.

\section{PETROGRAFIA}

Os basaltos do topo do derrame possuem granulação fina a muito fina, estrutura maciça ou variolítica e textura porfirítica a subafírica com matriz equigranular muito fina a afanítica.

Os basaltos que compõem o nível maciço central têm granulação fina a média, estrutura maciça e textura porfirítica a subafírica com matriz equigranular muito fina, subofítica e intergranular localizada.

A assembleia mineral destas rochas é constituída por cerca de $50 \%$ de andesina, 35 a $40 \%$ de augita e 5 a $10 \%$ de minerais opacos. É comum a ocorrência de apatita e grãos de olivina alterados. Ocorre também, principalmente no nível vesicular de topo, mesóstase cloritizada intersticial ou em microcavidades. As amígdalas encontradas, em maior abundância, no topo do derrame são preenchidas pricipalmente por celadonita e esmectita.

Microfenocristais de plagioclásio são classificados opticamente como andesina. Perfazem até $2 \%$ da rocha e apresentam dimensões entre 0,5 e 1,0 $\mathrm{mm}$ em seu eixo maior. São tabulares, geralmente, euédricos a subédricos e exibem limites relativamente nítidos e bem definidos (Figura 8a), também ocorrem microfenocristais subédricos, com limites pouco definidos e irregulares (Figura 8b). Em alguns microfenocristais de andesina são observadas microfraturas intragranulares sem preenchimento ou preenchidas por mesóstase cloritizada. Nos cristais com limites irregulares estas microfraturas são, aparentemente, mais comuns.

Na matriz, a andesina é ripiforme subédrica, com tamanho entre 0,05 a 0,4mm, geralmente não ultrapassa $0,3 \mathrm{~mm}$. Exibem limites menos regulares e pouco mais difusos que os microfenocristais. É comum que cristais de andesina ocorram como inclusões em grãos de minerais opacos, caracterizando textura poiquilítica (Figura 8c).

Os microfenocristais de augita têm entre 0,5 e $1,0 \mathrm{~mm}$ em seu eixo maior, são anédricos a prismáticos subédricos, podem apresentar contornos relativamente bem definidos (Figura 8d), ou bordas muito irregulares, com aparência de reabsorção e formação de grãos menores de plagioclásio e augita. Apresentam muitas fraturas intragranulares que podem estar preenchidas ou vazias.

Na matriz é predominante a granulação dos grãos de augita entre 0,05 e 0,1mm, com limites mais difusos e estão comumente inclusos ou aparentemente intercrescidos em grãos de magnetita. 

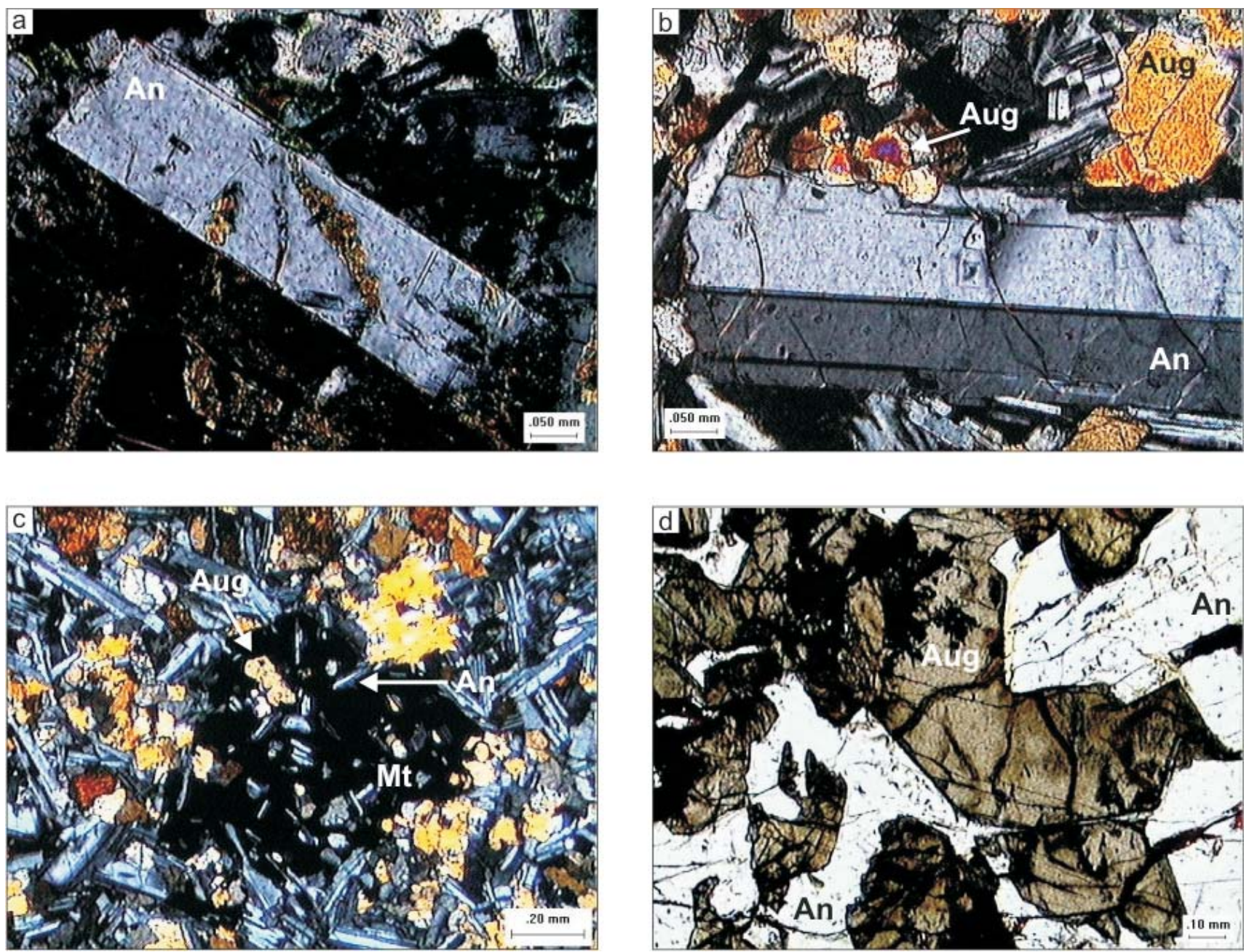

Figura 8 - Fotomicrografias de amostras de basalto. (a) Microfenocristal ripiforme de andesina (An), euédrico, exibindo limites bem definidos (nicóis X). (b) Microfenocristal ripiforme de andesina (An), subédrico, com limites irregulares e fraturas intragranulares, e grão anédricos de augita (Aug) (nicóis X). (c) Grão poiquilítico de magnetita (mt) com múltiplas inclusões de andesina (an) e augita castanho claro (aug) com granulação igual aos cristais da matriz. (nicóis X). (d) Grão anédrico de augita castanho escuro (Aug) com limites relativamente bem definidos com andesina (An) e fraturas intragranulares abertas. (nicóis II).

Os minerais opacos são óxidos, devido ao poder refletor intermediário observado em luz refletida. Em lâmina petrográfica, os óxidos apresentam três populações distintas (Figura 9). A primeira população ocorre na matriz, tem hábito cúbico geralmente subédrico a euédrico de tamanho entre 0,05 a 0,1mm. A principal característica é não apresentar inclusões. A segunda e terceira populações são compostas por grãos de textura poiquilítica, com inclusões de andesina e augita. Aparentemente há textura de intercrescimento entre augita e óxidos. Estas duas populações diferenciam-se pelo tamanho dos grãos. Grãos com tamanho entre 0,1 a $0,4 \mathrm{~mm}$ são considerados pertencentes à segunda população. Quando maiores que $0,5 \mathrm{~mm}$, pertencem à terceira população, que possui grãos com tamanhos de até $1,2 \mathrm{~mm}$. 


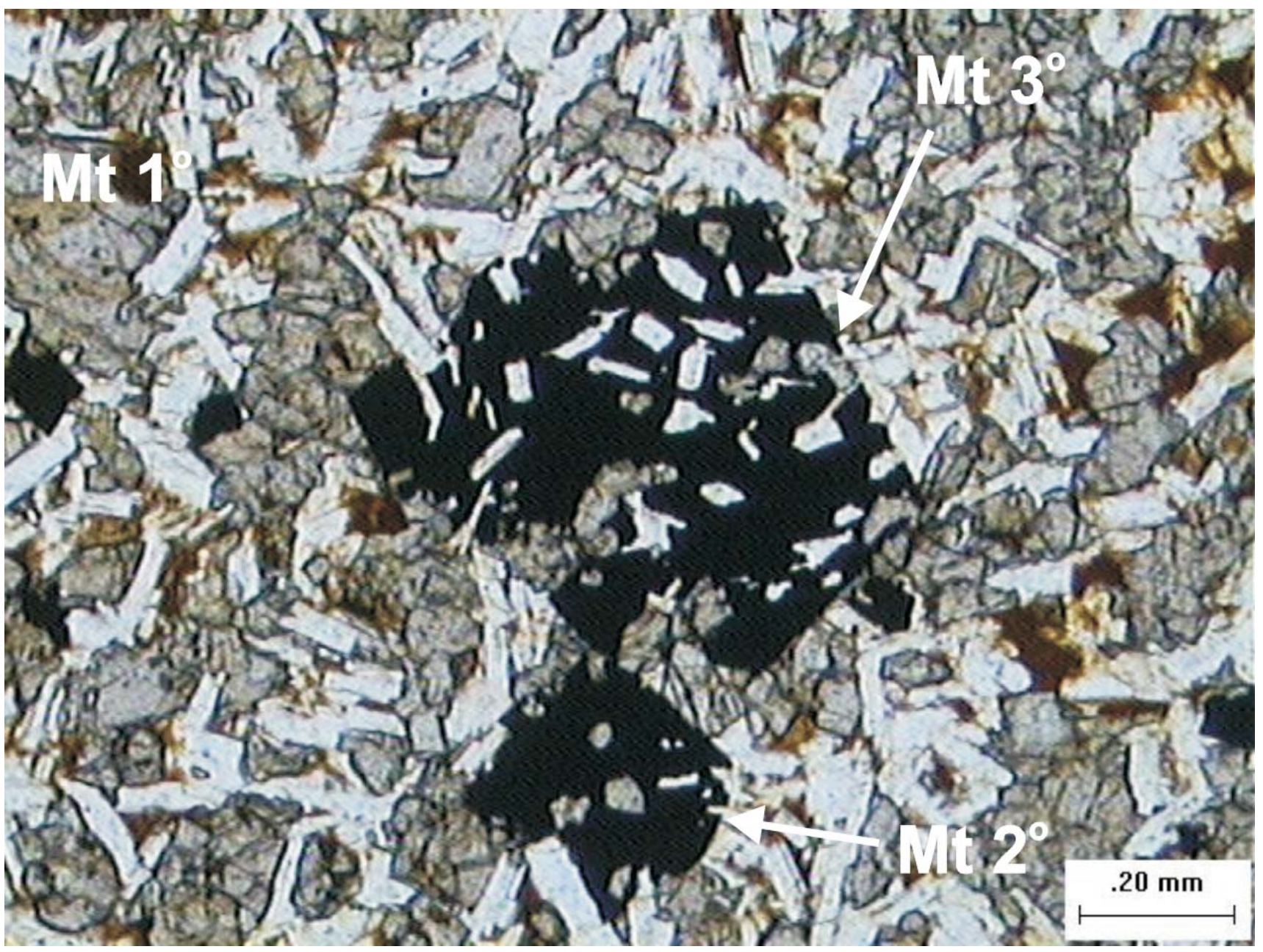

Figura 9 - Fotomicrografia em nicóis paralelos mostrando as três populações de magnetita definidas em MEV (microscopio eletrônico de varredura). A primeira é representada no centro esquerdo pelos grãos menores (Mt 1ㅇ) ), a terceira o grão maior no centro (Mt 3ㅇ) e a segunda população o grão menor a baixo (Mt 2ํ).

\subsection{Pegmatitos Básicos}

Os pegmatitos apresentam granulação média a grossa, estrutura maciça e textura porfirítica, subofítica a intergranular e matriz equigranular. A granulação dos pegmatitos, de forma geral, é cerca de 5 a 10 vezes maior que a dos basaltos encaixantes (Figura 10).

A assembleia mineral destas rochas é constituída por cerca de $45 \%$ de andesina, $35-40 \%$ de augita, $10-15 \%$ de minerais opacos. Em algumas rochas ocorre até $1 \%$ de apatita. Também ocorrem grãos de olivina parcialmente substituídos por esmectita.

Os microfenocristais de plagioclásio, classificados opticamente como andesina, perfazem até $2 \%$ da rocha e têm dimensões entre $4 \mathrm{~mm}$ até $8 \mathrm{~mm}$ em seu eixo maior. São tabulares, geralmente euédricos a subédricos quando exibem limites relativamente nítidos. A maior parte dos cristais apresenta limites irregulares e reativos, a exemplo dos cristais de plagioclásio do basalto encaixante. Esta possível alteração das bordas pode variar de relativamente tênue até bastante pervasiva.

Os cristais de andesina pertencentes à matriz dos pegmatitos têm tamanhos entre 0,5 a $1,5 \mathrm{~mm}$, são ripiformes subédricos e exibem, por vezes, contatos mais nítidos e definidos que os microfenocristais. 


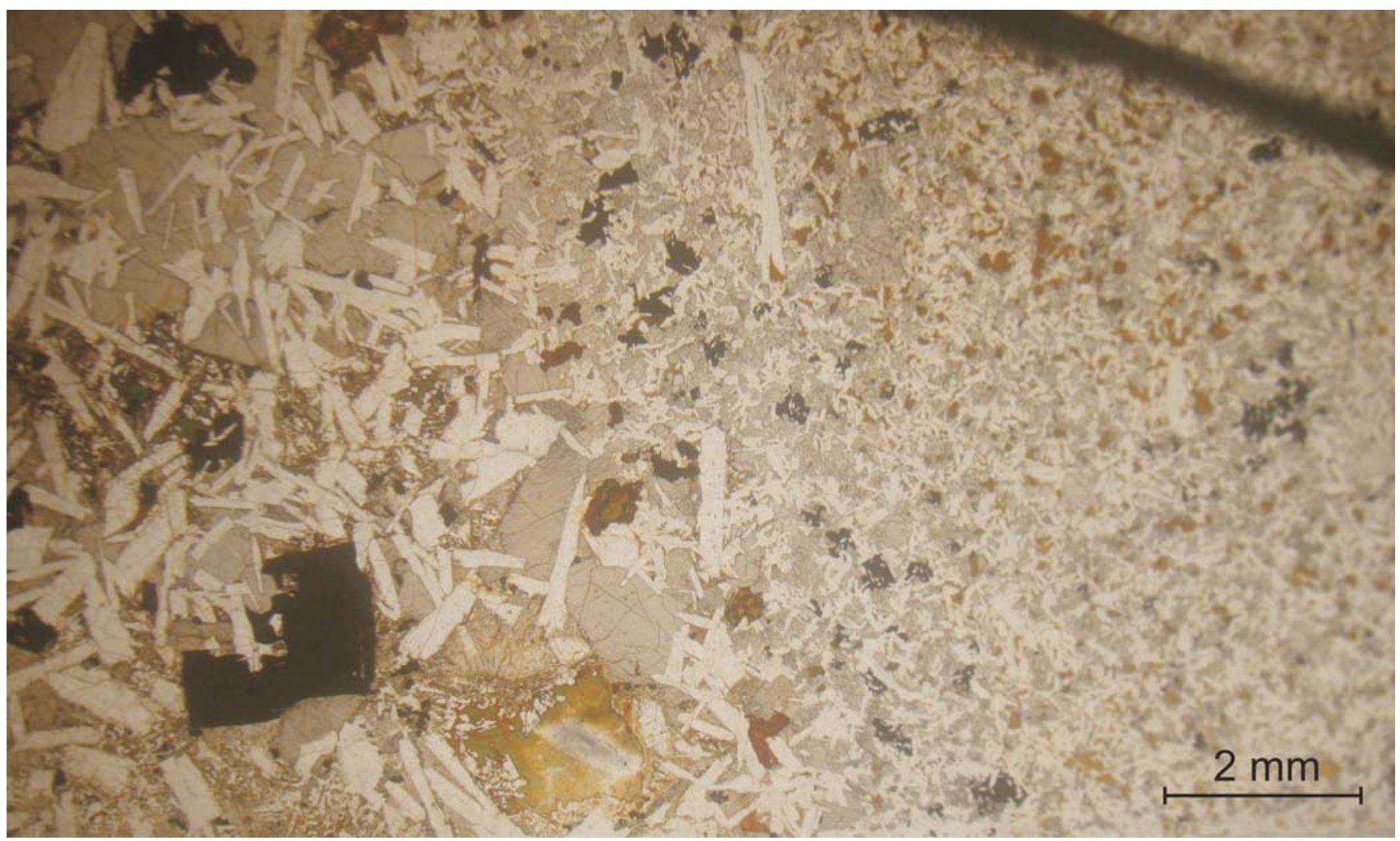

Figura 10 - Fotomicrografia capturada em petroscópio óptico (nícois //) exibindo contato irregular e gradacional entre pegmatito (esquerda) e basalto encaixante (direita).

Porções da rocha com relativa maior quantidade de andesina em relação à augita definem a ocorrência, não rara, de textura intergranular (Figura 11a). É comum a ocorrência de fraturas intragranulares preenchidas por mesóstase cloritizada ou sem preenchimento.

Os cristais de andesina do pegmatito tipo $B$, de

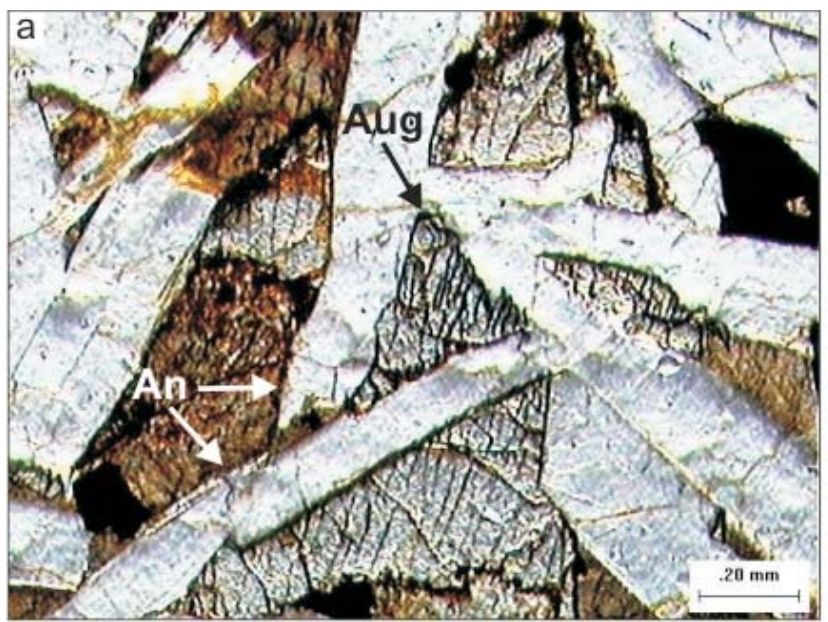

forma geral, não apresentam alteração hidrotermal ou supergênica, salvo onde ocorre pouca sericitização. Por outro lado, cristais do tipo A podem apresentar intensa alteração dos limites dos grãos, que se apresentam reativos. Pode ocorrer uma interação entre plagioclásio e augita parcialmente cloritizada definindo textura simplectítica (Figura 11b).

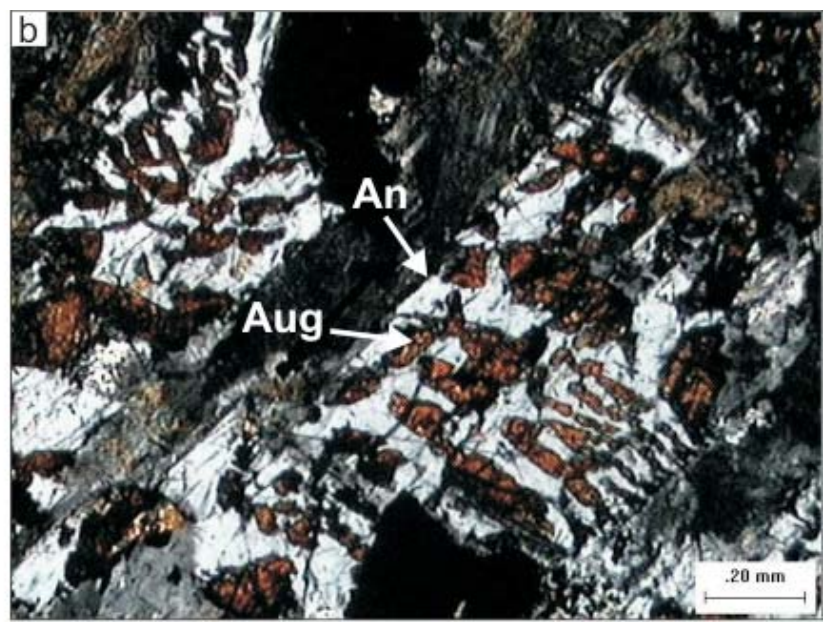

Figura 11 - Fotomicrografias de amostras de pegmatito básico. (a) Fotomicrografia em nicóis // mostrando no centro, grão de augita (Aug) envolto por cristais de andesina (An), configurando textura intergranular. (b) Fotomicrografia em nicóis X mostrando intercrescimento entre cristais de andesina (An) e augita (Aug). Esta interação define textura simplectítica. 
Os maiores fenocristais de augita podem chegar até $1 \mathrm{~cm}$ de comprimento em seu eixo maior, cerca de dez vezes maiores que os microfenocristais de augita presentes no basalto encaixante. Estes minerais, são anédricos a subédricos, com limites irregulares e podem estar parcialmente alterados para clorita. É comum a inclusão de cristais ripiformes de plagioclásio nestes microfenocristais (Figura 12a).

Na matriz, predominam grãos de augita com cerca de $1 \mathrm{~mm}$, com limites irregulares e parcialmente cloritizados (Figura 12b). Grande parte dos grãos são intensamente fraturados. Estas fraturas podem estar preenchidas por clorita.

Os mineriais óxidos, a exemplo do que ocorre com os basaltos encaixantes, ocorrem em três populações. A primeira ocorre na matriz com hábitos cúbicos e octaédricos, aciculares, prismáticos subédrico a euédrico (definidos no MEV como magnetita e ilmenita). Não apresentam inclusões. Esta população é composta por grãos de tamanhos entre 0,05 a 0,2mm.

A segunda e terceira populações ocorrem às expensas da matriz, crescem englobando os minerais da matriz, com textura claramente poiquilítica, como ocorre no basalto encaixante.

A segunda população é composta por grãos com muitas inclusões de andesina e augita. Os grãos têm hábito cúbico subédrico e granulação entre 0,5 e 1,0 mm. Alguns grãos apresentam aparente intercrescimento com grãos de augita.

A terceira população apresenta grãos com tamanhos superiores a $1,0 \mathrm{~mm}$, podendo chegar, mais raramente, até $1 \mathrm{~cm}$. Estes grãos além de hábitos cúbicos com textura poiquilítica, exibem também hábito esquelético (Figura 12c) e acicular (Figura 12d), em MEV definidos como magnetita e ilmenita (respectivamente).
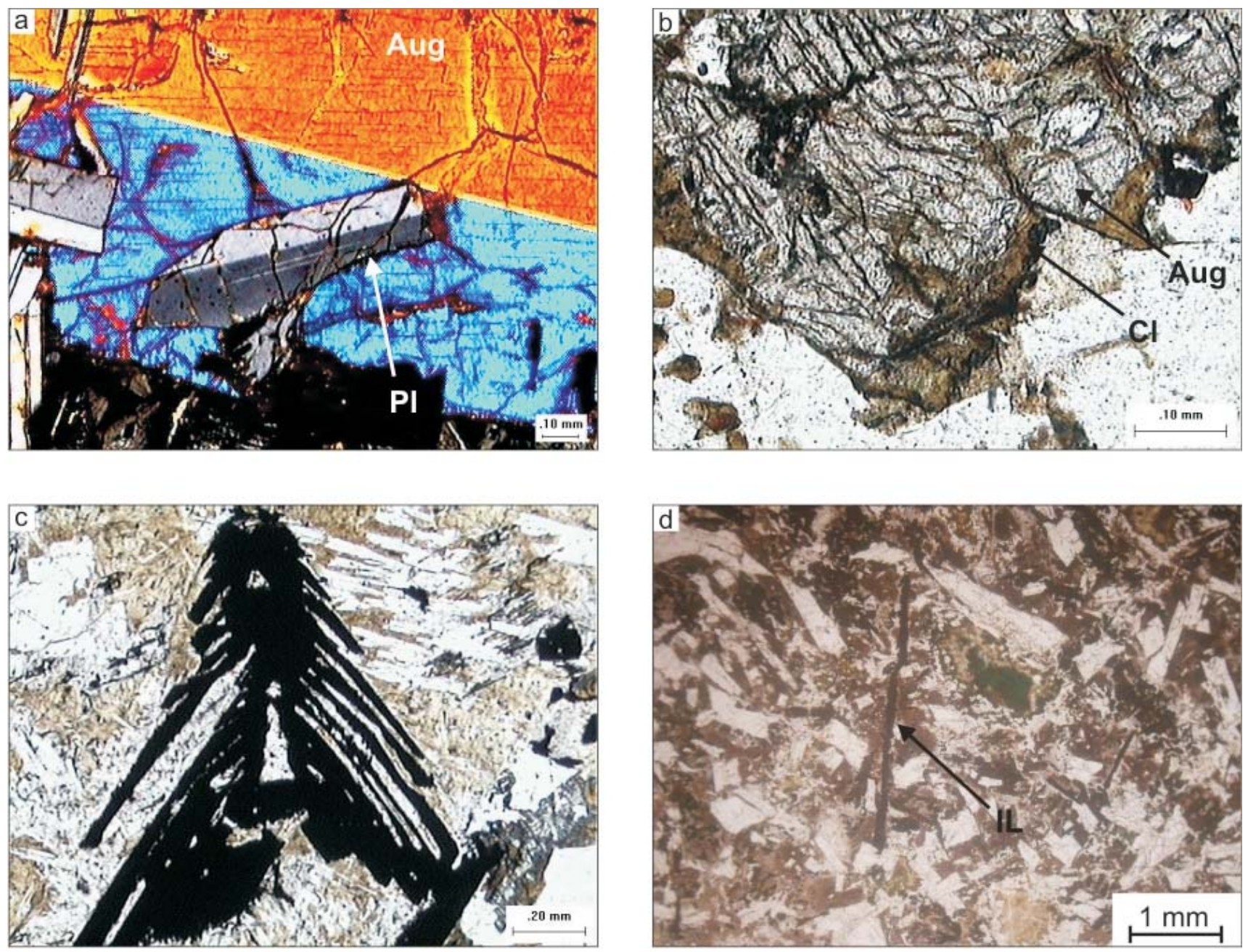

Figura 12 - Fotomicrografias do pegmatito básico. (a) Fotomicrografia em nicóis X mostrando cristal de plagioclásio (PI) ripiforme subédrico incluso em microfenocristal de augita (Aug). (b) Fotomicrografia em nicóis // mostrando grão de augita (Aug) intensamente fraturado com limites irregulares, parcialmente alterada para clorita (Cl). (c) Fotomicrografia em nicóis // mostrando mineral opaco da terceira população com hábito esquelético. (d) Fotomicrografia capturada em petroscópio (nicóis //), mostrando o óxido ilmenita (IL), de terceira população, com hábito acicular. 


\section{DISCUSSÕES E CONCLUSÕES}

A diminuição da temperatura durante a evolução de um derrame condiciona, devido à variação da viscosidade da lava, a formação de diferentes estruturas internas. A forma, espaçamento e quantidade de fraturas, bem como o número, tamanho e distribuição de vesículas ao longo do derrame estão diretamente relacionados com o tipo de resfriamento ao qual o derrame foi submetido.

A arquitetura do derrame Salto do Lontra com distribuição e arranjo das estruturas internas, como amígdalas e vesículas e padrão de fraturas bem definidos, pode defini-lo como associado aos derrames tipo II descritos por Gomes (1996) e do tipo pahoehoe, conforme classificação de Macdonald (1953), com estruturação interna dividida em crosta superior, núcleo e crosta inferior.

As distintas feições estruturais encontradas nos diferentes níveis denotam que cada horizonte teve uma evolução diferenciada durante o resfriamento. A estrutura interna do derrame Salto do Lontra sugere a ocorrência de processos de inflamento, no sentido de Hon et al. (1994), com o desenvolvimento de uma crosta rígida e vesiculada que constitui o nível vesicular de topo abaixo da qual, novos pulsos de magma são incorporados.

O padrão de distribuição das bolhas no nível vesicular e a espessura total do derrame, comparados aos estudos de Self et al. $(1996,1998)$, indicam que o derrame Salto do Lontra foi formado durante processos ativos de inflamento. Seguindo o modelo evolutivo de Self et al. (1998) para o emplacement de derrames espessos, entende-se que as rochas do derrame Salto do Lontra teriam sido formadas em quatro importantes estágios evolutivos (Figura 13).

O primeiro estágio (Figura $13 \mathrm{I}$ ) relacionado ao inicio do processo de inflamento com fluxo de lava restrito e lenta movimentação do derrame, onde as primeiras vesículas são formadas logo após o extravasamento da lava. Quando há o acumulo dessas vesículas no topo do nível superior do derrame originamse as zonas vesiculares horizontais.
No derrame salto do Lontra as zonas vesiculares horizontais correspondem ao nível vesicular de topo, o que sugere novamente que este derrame foi formado por processos ativos de inflamento.

Durante o inflamento, estágio evolutivo representado pela Figura $13 \mathrm{II}$, a lava movimenta-se em direção contrária à fenda pela qual extravasou, seguido de espessamento do derrame, com soerguimento da superfície de topo e crosta.

No interior do corpo de lava que se movimenta, as diferenças na distribuição de calor se refletem em comportamentos reológicos diferentes para as bordas e o núcleo. Enquanto o núcleo permanece plástico e se movimenta a taxas mais rápidas, as bordas vão se tornando cada vez mais rígidas, devido ao contato com a superfície e o ar. Ocorrem então, quebras da frente de solidificação possibilitando o crescimento do derrame em extensão lateral.

Uma vez que a movimentação da lava cessa (Figura $13 \mathrm{III}$ ), uma série de outros processos se desenvolve no interior do derrame em resfriamento. De acordo com Self et al. (1996, 1998), os lençóis de vesículas formam-se após a estagnação do derrame, quando o processo de inflamento não é mais atuante. Estas estruturas são formadas pela ascensão de voláteis na forma de diápiros e se acumulam na base da crosta superior. No derrame Salto do Lontra estas estruturas são representadas por vesículas e amígdalas arredondadas e alongadas horizontalmente.

Em um derrame em processo de resfriamento, já em mais baixas temperaturas e maior grau de cristalinidade, a taxa de contração começa a exceder a capacidade de fluxo da lava, gerando um acúmulo de stress térmico que é resolvido pela deformação plástica ou pela ruptura frágil, dependendo do grau de cristalização da rocha (Gomes, 1996). Estas rupturas possibilitam o acumulo de material residual que se solidificaria na forma de pegmatitos básicos.

A história do alojamento do derrame fica preservada na distribuição das vesículas longitudinalmente ao derrame, nos padrões de fraturas da lava resfriada e no posicionamento dos corpos de pegmatito básico (Figura 13 IV). 


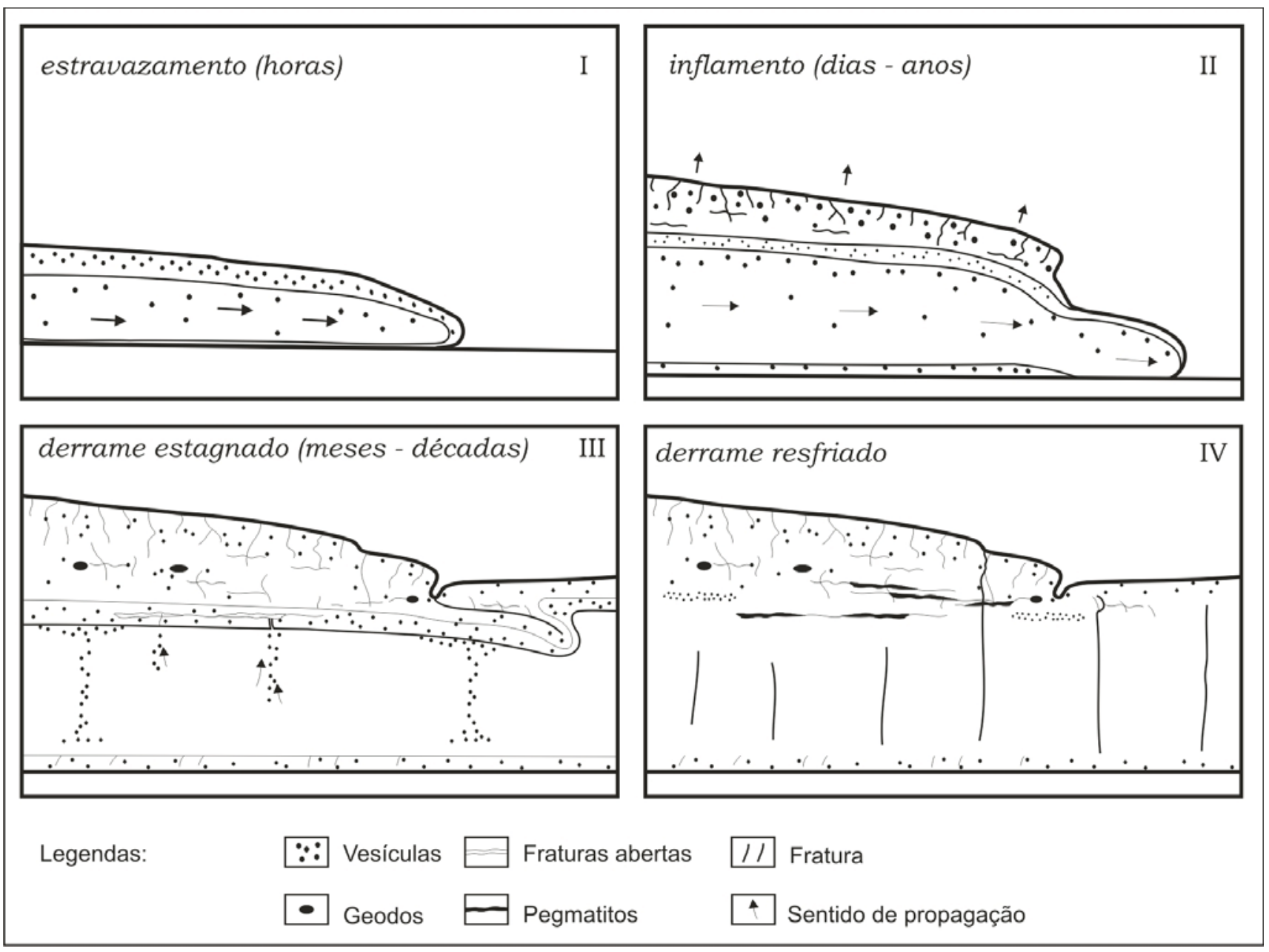

Figura 13 - Estágios evolutivos de um derrame desde o início do extravasamento dos primeiros fluxos de lava (I), crescimento endógeno (II), estagnação e processos magmáticos (III) e configuração final do derrame. (Figura modificada de Self et al. 1998).

As diferenças texturais e estruturais entre os horizontes de um derrame são reflexos da dinâmica de resfriamento diferenciada para cada um.

Os dois grupos de rochas, basaltos e pegmatitos, diferenciam-se principalmente pela porcentagem modal dos minerais primários e secundários, pela granulação e pela presença de amígdalas nos pegmatitos tipo $A$.

A formação dos microfenocristais normalmente está relacionada à diminuição da pressão durante a ascensão do magma. Segundo Hooper et al. (2007) os microfenocristais de andesina, encontrados nos pegmatitos básicos e nos basaltos encaixantes podem estar relacionados à atuação de processos de fracionamento do magma.

A granulação da matriz do basalto é menor no nível vesicular de topo e de base e relativamente maior no nível maciço central, indicando que o derrame sofreu resfriamento das bordas para o centro.

Resumindo, as características internas do derrame Salto do Lontra sugerem a ocorrência de processos de inflamento, com o desenvolvimento de uma crosta rígida e vesiculada que constitui o nível vesicular de topo abaixo da qual, novos pulsos de magma foram incorporados. O padrão de distribuição das bolhas no nível vesicular indica a sua formação durante o processo ativo de inflamento. O comportamento das fraturas no nível maciço central denota heterogeneidade no resfriamento da base para o topo do nível, tendo a base do nível um resfriamento mais rápido que a porção mediana; a geração de grandes prismas indica que o derrame teve um resfriamento lento. A presença de pegmatitos básicos indica a atuação de liquido residual, mais evoluído, na fase final do inflamento e marca o emplacement destas lavas 


\section{Referências bibliográficas}

ARIOLI, E.E.; LICHT, O.A.; VASCONCELLOS, E.M.G.; SCHRANK, A. 2008. Significado Exploratório de Anomalias Geoquímicas de Ni-Cu-EGP e Metais Associados em Basaltos da Formação Serra Geral, Estado do Paraná. In: Congresso Brasileiro de Geologia, 44. Anais, p. 563.

DUTRA, C. R. 2009. Caracterização morfológica e petrográfica do derrame Salto Segredo - Província Magmática do Paraná - PR. Dissertação (mestrado) UFPR.

FERREIRA, C.H.N.; DUTRA, C.H.; GOMES, M.E.B.; MESQUITA, M.J., BONGIOLO, E.M.; ARIOLI, E.E. 2008. Características estruturais de um derrame e estratigrafia da região de Salto Segredo,.In: IV Simpósio de Vulcanismo e Ambientes Associados, Foz do Iguaçu.

GOMES, M.E.B. 1996. Mecanismos de resfriamento, estruturação e processos pós-magmáticos e basaltos da Bacia do Paraná - região de Frederico Westphalen (RS - Brasil). Tese (doutorado) - CPGeo - UFRGS e Univ. Poitiers (França).

HON, K.; KAUAHIKAUA, J.; DENLINGER, R.E.; MACKAY, K. 1994. Emplacement And Inflation Of Pahoehoe Sheet Flows: Observatiions And Measurements Of Active Lava Flows On Kilauea Volcano, Hawaii. Geol. Soc. Am. Bull. 106: 351-370.

HOOPER, P.R.; CAMP, V.E.; REIDEL, S.P.; ROSS, M.E. 2007. The origin of the Columbia River Flood Basalt Province: plume versus nonplume models. In: FOULGER, G.R. \& JURDY, D.M. (editors). Plates, plumes and planetary process: Boulder, Colorado. Geol. Soc. Amer. Special. Paper: 430.

KONTAK, D.J.; DE WOLFE, M.Y.; YOUNG, D.E.; DOSTAL, J. 2004. Late-Stage Crystallization History of the Jurassic North Mountain Basalt, Nova Scotia, Canadá. I. Textural and Chemical Evidence for Pervasive Development of Silicate-Liquid Immiscibility. The Canadian Mineralogist, V. 40, N. 5, P. 1287-1311.

MACDONALD, G.A. 1953. Pahoehoe, a`a`and block lava. Amer. Journ. Sci. 251,169-191.

SELF, S.; THORDARSON, T.; KESZTHELYI, L.; WALKER, G.P.L.; HON, K.; MURPHY, M.T. 1996. A New Model For The Emplacement Of Columbia River Basalts As Large, Inflated Pahoehoe Lava Flow Fields. Geophysical Research Letters, Vol. 23. No. 19. 2689 2692.

SELF, S.; KESZTHELYI, L.; THORDARSON, T. 1998. The Importance Of Pahoehoe. Annu. Rev. Earth Planet. Sci. 26:81-110.

VASCONCELLOS, E.M.G.; LICHT, O.A.B.; BRAGA, L.S.; BITTENCOURT, A.V.L. 2001. Gabros da Bacia do Paraná: aspectos petrográficos e geoquímicos. In: VIII Congresso Brasileiro de Geoquímica; I Simpósio De Geoquímica dos Países Do Mercosul, Curitiba. Anais... Curitiba: Sociedade Brasileira de Geoquímica. 